Journal of Development and Communication Studies, Vol. 8. No. 1, January -June, 2021 ISSN (Online \& Print): 2305-7432. http://www.devcomsjournalmw.org

\title{
Influence of Message Content in Persuasive Communication on Adoption of Routine Immunisation of Children Aged 0-5 years in Bomet County, Kenya
}

Mary Amatu, School of communication and developmental studies, Jomo Kenyatta University Nairobi, Kenya \& Department of clinical medicine, Mount Kenya University of Science and Technology Email: amatu.mary@gmail.com, Hellen Mberia, School of communication and Developmental Studies, Jomo Kenyatta University, Nairobi, Kenya, \& Kaylo Wa Ngula, Department of Mass communication, Chuka University, Chuka, Kenya.

\begin{abstract}
An estimated two to three million annual deaths from vaccine preventable diseases (VPDs) are prevented through immunisation. Currently about 19.5 million infants miss out on routine immunisation globally. We carried out a study on the role of message content in persuasive communication on adoption of routine immunisation services. The study employed a mixed method research design. A sample of 384 caregivers was used. Data was collected using interviewer administered questionnaires and Key Informant Interviews. The key informants interviewed were taken with sub-county medical officer of health, health promotion officer and EPI coordinator. Both descriptive and inferential statistics were applied in the analysis. The study findings were that message content had positive influence on adoption of routine immunisation. The study recommended that routine immunisation messages be made frequently available, targeted and tailored to the caregivers. Secondly, the community should be involved in advocacy towards adoption of routine immunisation, to create ownership and adoption sustainability. Additionally, health workers should be motivated towards good practice in health worker-client communication, specifically, persuasive communication to build trust from the caregivers. The researcher recommends comparative studies should be conducted, comparing the well performing counties with Bomet County, Kenya.
\end{abstract}

Key words: persuasive communication, immunisation, message content 


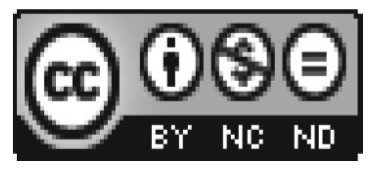

(C) 2020. The authors. This work is licensed under the Creative Commons Attribution 4.0 International License (CC-By-NC-ND). Users may freely share and redistribute this work provided that the author and the Journal of Development and Communication Studies are fully acknowledged. Users may not tweak or remix and offer this work for sale. The full license may be accessed at https://creativecommons.org/licenses/by-nc-nd/4.0/

To cite this article: Amatu, M., Mberia, H. \& wa Ngula, K. (2021). Influence of Message Content in Persuasive Communication on Adoption of Routine Immunisation of Children aged 0-5 years in Bomet County, Kenya. Journal of Development and Communication Studies, 8(1), 185-222 https://dx.doi.org/10.4314/jdcs.v8i1.9

\section{Introduction}

A fully immunised child is an ambitious but practical indicator that should be used to measure health progress. According to UNICEF statistics, there has been a recognizable reduction of infant deaths caused by vaccine preventable diseases (VPDs) over the recent years. VPDs are life threatening and delay a country's development. A major strategy to reduce vaccine preventable disease is by coming up with and reviewing communication plans with well-defined strategies that will ensure fully immunised child (FIC) in all settlements, (UNICEF, 2016). In 2017, Kenya's national immunisation coverage was $65 \%$ for fully immunised child. The top performing counties at coverage above $80 \%$ were Kiambu, Turkana and Nairobi. Three counties $(6 \%)$ had coverage of approximately 50\%. The worst performing counties were Trans Nzoia, Mandera (53\%) and Tana River (55\%) and Bomet 50\%), (WHO 2018). Bomet was purposely selected for the study for this reason of being the lowest performing.

According to WHO (December 2017), Bomet County fully immunised children were at $50 \%$, against the national target of $90 \%$ and above. This low coverage was being witnessed inspite of the fact that the government of Kenya has put key focus on these life-threatening VPDs as other peer countries do. The report further stated that the reasons for this coverage was not attributed to vaccine or commodity stock outs as there had been none reported in the County and attributed the low adoption to knowledge gap and low literacy levels among the care givers that hinders effective communication. This puts the County at a very high risk of children suffering from the VPDs, which are also communicable (MOH HIS, 2018). There have been studies conducted in this field:- Harvey et al., (2016) conducted a study on parental reminder, recall interventions to improve childhood immunisation adoption: A systematic review and meta-analysis. Oku, et al., (2017), studied factors affecting the implementation of childhood vaccination communication and educational strategies in Nigeria and found that message, channel, sender and receiver characteristics 
influenced adoption of routine immunisation. In another study by Heather M. (2017), on parents' and informal caregivers' views and experiences of communication about routine childhood vaccination, the findings too support these communication characteristics as a factor in adoption. These studies among others supported the role of the variables on adoption of vaccination or lack thereof. The scholars stated that when these factors are addressed, there is assurance of adoption of routine immunisation services.

The study target population was caregivers seeking services for children aged $0-5 y e a r s$ from the five sub-county hospital. The number estimated to be 1,747 per month (Bomet County health records 2018). The study used two theories: Elaborate likelihood mode of persuasion (ELM) and diffusion of innovation theory. The study used convergent parallel mixed method design to examining the influence of message content, channel, sender and receiver characteristics on the adoption of routine immunisation as independent variables.

\section{Study objectives}

To determine persuasive communication factors influencing adoption of routine immunisation of children aged 0-5 years in Bomet County, Kenya. The specific objective of the study was to establish the influence of message content on adoption of routine immunisation of children aged 0-5 years in Bomet County. Moreover, the study adopted the following null hypothesis

H01: There is no significant influence of message content on adoption of routine immunisation of children aged 0-5 years in Bomet County, Kenya.

\section{Methodology}

The study used mixed method design, specifically convergent parallel mixed method design. This design entails that the researcher concurrently conducts the quantitative and qualitative elements in the same phase of the research process, weighs the methods equally, analyzes the two components independently, and interprets the results together.

The target population for this study was caregivers who were seeking services for children 0-5years at the targeted sub-county hospitals. The Sub-county pediatric health records were perused to find the number of these children that had been attended to three months prior to the study. An average was calculated to estimate the number who were attended to per month (Table1). This translated to 1,747 children age 0-5 years seen in the five Sub-counties (Bomet County health records 2018).

Table 1: Average number of children seeking services per Sub-County

\begin{tabular}{ll}
\hline Sub-County & Number of children treated \\
\hline Sotik & 400
\end{tabular}


Bomet East

Bomet central 332

Konoin 332

Chepalungu $\quad 387$

TOTAL

1,747

Source: Bomet County Health records

\section{Sampling frame}

The sample was drawn from the day's outpatient/paediatric clinic register in the five sub-counties; Sotik, Bomet East, Bomet Central, Konoin and Chepalungu. Since the sampling was done from each Sub-County Hospital, the researcher picked the study participants randomly.

\section{Sample}

A sample size should have characteristics that should enable generalisation of the study findings and subsequent predictions. The target population was care givers (1549years) seeking care for children aged 0-5years to seek services at the sub-county hospital, estimated to be 1747 (Bomet County health records 2018). Sample size was determined according to Fischer et al. (1991). The sample size was calculated using the formula:

$\mathrm{n}=\quad \begin{aligned} & \mathrm{Z}^{2} \mathrm{pq} \\ & \mathrm{d}^{2}\end{aligned}$

Where:

$\mathrm{Z}=$ The standard deviate (1.96)

$\mathrm{n}=$ Desired sample size

$\mathrm{p}=$ Percentage of population with the desired characteristics

$\mathrm{q}=1-\mathrm{p}$

$\mathrm{d}=$ Margin of error $(0.05)$

Therefore:

$$
\begin{aligned}
n & =(1.96)^{2}(0.50)(0.50) \\
& (0.05)^{2} \\
& =384
\end{aligned}
$$

Considering the total sample size and the population size in each sub-county, the sample for each sub-county was determined proportionately as indicate on table 2.

Table 1: Proportionate sampling of study sample

\begin{tabular}{lllll}
\hline Sub-County & Number seen & $\mathbf{\%}$ & Participants & $\begin{array}{l}\text { Sampling } \\
\text { interval }\end{array}$ \\
\hline Sotik & 400 & 23 & 88 & 5 \\
Bomet East & 296 & 17 & 65 & 5 \\
Bomet central & 332 & 19 & 73 & 5 \\
Konoin & 332 & 19 & 73 & 5
\end{tabular}




\begin{tabular}{lllll} 
Chepalungu & 387 & 22 & 85 & 5 \\
TOTAL & $\mathbf{1 , 7 4 7}$ & $\mathbf{1 0 0}$ & $\mathbf{3 8 4}$ & \\
\hline
\end{tabular}

Multistage sampling technique was used to get the study participants. Bomet County, the primary sampling unit, was purposively selected following a WHO report of 2017 that portrayed the County as poorly and the least (at 50\% fully immunised children coverage) performing in adoption of vaccination service of children aged 0-5 years. The 384 study participants were allocated to the five Sub-counties proportionately, depending with the average number of children 0-5 years attended to in the Subcounty hospitals monthly, (table 2). Systematic random sampling was done. Based on this, the first caregiver who was attended to was requested to participant in the study. If the participant declined, the next one was approached until one was gotten. Using sampling interval of five, the process was repeated until a desired sample size was achieved. This selection processes was facilitated by the facility in-charge or a representative and the interview was held at a venue within the health facility. In addition, the researcher conducted KII interviews with health workers. The KII were selected using purposive sampling method.

\section{Data collection instruments and procedure}

This study conducted data triangulation and used cross-sectional data collection procedure using an interviewer administered questioner. A semi-structured interviewer administered questionnaire, with a mixture of open and closed ended questions was used, which was designed in English.

\section{Reliability and Validity}

To establish reliability of the instrument, the questionnaire was pre-tested to a sample of $38(10 \%)$, caregivers who had taken children aged 0-5years to a neighboring Kipsigis Sub-county hospital in Kericho County. The alpha test for all the items was found to be reliable for measurement because the reliability coefficient values were found to be above the recommended threshold of 0.7. To test for validity, Factor loadings test was carried out. None of the item recorded factor loading lower than 0.50. Therefore, all items were considered valid for the study

\section{Data analysis and presentation}

The qualitative data was trascribed according to the identified themes and edited then analysed qualitatively in the form of narratives. Descriptive statistics such as frequencies, percentiles and mean were used to present data. The findings of the analysis are presented using tables with frequencies and percentage. The second category of analysis was inferential statistics. The statistical tool for the inferential analysis was logistic regression. 


\section{Regression model}

$\mathrm{H}_{1}$ : There is significant influence of message content on adoption of routine immunisation of children aged 0-5 years in Bomet County

$\mathbf{Y}=\aleph_{0}+\aleph_{1} \mathbf{X}_{1}+\grave{\mathbf{e}}$

Whereby;

$\mathbf{Y}=$ Adoption of routine immunisation of children aged 0-5 years in Bomet County

$$
\begin{aligned}
& \boldsymbol{\aleph}_{0}=\text { Constant } \\
& \boldsymbol{B}_{1}=\text { Coefficients of determination } \\
& \mathbf{X}_{1}=\text { Message content } \\
& \grave{\mathbf{e}}=\text { Error term }
\end{aligned}
$$

\section{Ethical consideration}

Ethical clearance was sought from Mount Kenya University Ethical board (MKU, 0360 Feb 2020). Upon the receipt of ethical clearance, NACOSTI study license was sought and granted License No: NACOSTI/P/20/3696. Written informed consent was obtained from the study participants. Further data analysis was done in such a way that no information identifiers were included.

\section{Findings}

\section{Response rate}

Data was collected from all the five Sub-counties of Bomet County. During data cleaning, only 365 questioners out of the 384 participants interviewed, had questioners properly completed and therefore qualified for data analysis. This translated to $95.1 \%$ response rate (table 3). Based on these findings, the response rate was adequate per the general rule of thumb of good response rate of $50 \%$ and above.

Table 3: Response Rate

\begin{tabular}{lll}
\hline Response Rate & Frequency & Percent \\
\hline Completed & 384 & $100 \%$ \\
Fit for analysis & 365 & $95.1 \%$ \\
Spoilt & 19 & $4.9 \%$ \\
Total & $\mathbf{3 8 4}$ & $\mathbf{1 0 0} \%$ \\
\hline
\end{tabular}


The majority were in the age bracket of $19-25$ at $42.2 \%$. This was closely followed by age $26-30$ at $21.9 \%$. Age $14-18$ indicated a percentage of $13.3 \%$. Age $31-35$ recorded a percentage of $11.0 \%, 36-40$ then $41 \&$ above recorded $5.8 \%$ for each case. The finding clearly suggests many of the mothers who were the main target of population as far this study is concerned, many of them manly comprised of the youths. This study agrees with one carried by Kachikis et al., (2020), that found maternal age is a factor influencing adoption of routine immunisation. On the question of marital status, it was established that majority of the respondent are married and this was supported by $61.4 \%$. This is in spite of the fact that a significant percentage of them being in the age bracket of 14 - 18 year (teenagers), forming $36.6 \%$ of the population of single mothers. However, this study did not find any significant difference in attitude or adoption of routine immunisation between the single and married caregivers (table 4). This differs with a study by Esohe et al. (2016) that found female caregivers that were married had good attitude towards adoption of immunisation services.

The question on the number of children, $49.3 \%$ had between $4-6$, followed by $35.0 \%$ having between $1-3$ and $15.6 \%$ had above 6 children. $75.3 \%$ had one child below 5 years with a significant percentage (20\%), having two children below 5 years. The study established that those participants with 1-3 children had the highest adoption rate compared to those with a higher number. This study agrees with one by Hayles et al., (2015), that found that those women with higher number of children tended to ignore taking children for vaccination (Table 4).

The study was also interested in establishing the level of education and occupation of the respondents and the finding found that majority of the respondent had primary level of education at $53.7 \%$, followed by secondary level those had attained only primary level of education with only $8.8 \%$ having attained tertiary level of education and lastly those who had no level of education were $1.9 \%$ which was the least. finding on table 4 . The higher the level education, the higher the likelihood of adoption of routine immunisation (P value of 0.001 ). This study is in agreement with a study that found that children of caregivers with lower maternal education were less likely to be fully vaccinated (Lisa et al., 2014). Additionally, the study agrees with Imoh (2014), found that education level determines immunisation coverage as the study found that coverage was higher in areas where most caregivers generally had knowledge about vaccine preventable diseases symptoms.

Further, it was found that $36.9 \%$ of the respondents reported to be housewives, 29.9 were farmers, with the $14.1 \%$ being self-employed and $10.1 \%$ were in formal employment (table 4). It was obvious that there was high levels of dependency which may affect adoption of routine immunisation. The occupation of a caregiver was not found to have an effect on adoption of routine immunisation in this county. However, this study contradicts with studies that have documented that caregiver occupation 
may determine adoption of routine immunisation. This analogy can be related with other studies such as one on routine immunisation review in Nigeria, O'Connell, M., \& Wonodi, C. (2015) found that caregivers who were employed were found to adopt routine immunisation compared to their counterparts who were housewives.

Forty-nine percent have between 4-6 children, followed by with $35.1 \%$ with 1 3 children. Additionally, $75 \%$ had one child below five years (table 4 ). The higher the number of children and specifically those with more below five years adopted less the routine immunisation ( $\mathrm{P}$ value of 0.004 ). The number of children was also found to significantly influence adoption of routine immunisation (Kaufman et al., 2017).

Concerning $57.3 \%$ were Protestants, a significant number (37.3\%) catholic, Muslims 5.5\% and others taking up the remaining 6.8\% (table 4). Region had an influence on adoption with those that were Catholics having lower adoption compared to the others ( $p$ value 0.003). They were found to be the same group that had wrong information on side effects. Studies have found a relation between routine immunisation adoption and religion. Conspiracy theories linking vaccination and fertility control and/or sterilisation have been propounded and promoted by religious leaders (Anyene, B. 2014).

Table 4: Demographic information

\begin{tabular}{llll}
\hline Age in years & Frequency & Percent & Cumulative Percent \\
$14-18$ & 49 & 13.4 & 13.4 \\
$19-25$ & 154 & 42.2 & 55.6 \\
$26-30$ & 80 & 21.9 & 77.5 \\
$31-35$ & 40 & 11.0 & 88.5 \\
$36-40$ & 21 & 5.8 & 94.2 \\
$41 \&$ above & 21 & $\mathbf{1 0 0}$ & \\
Total & 365 & $\mathbf{1 0 0}$ & \\
\hline Marital status & & & \\
Single & 141 & 38.6 & 38.6 \\
Married & 224 & 61.4 & $\mathbf{1 0 0 . 0}$ \\
Total & 365 & $\mathbf{1 0 0 . 0}$ & \\
\hline Occupation & & & \\
Housewife & 135 & 36.9 & 36.9 \\
Farmer & 109 & 29.9 & 66.8 \\
Self-employed & 51 & 14.1 & 80.9 \\
Employed & 70 & 19.1 & $\mathbf{1 0 0}$ \\
Total & 365 & $\mathbf{1 0 0}$ & \\
\hline Level of education & & & \\
Never been to school & 7 & 1.9 & 1.9 \\
\hline
\end{tabular}




\begin{tabular}{llll}
\hline Primary education & 196 & 53.7 & 55.6 \\
Secondary education & 130 & 35.6 & 91.2 \\
Tertiary education & 32 & 8.8 & $\mathbf{1 0 0}$ \\
$\quad$ Total & $\mathbf{3 6 5}$ & $\mathbf{1 0 0}$ & \\
\hline $\begin{array}{l}\text { Religion of respondents } \\
\text { Catholic }\end{array}$ & 136 & 37.3 & 37.3 \\
$\quad$ Protestant & 184 & 50.4 & 87.7 \\
Muslim & 20 & 5.5 & 93.2 \\
Others & 25 & 6.8 & $\mathbf{1 0 0}$ \\
Total & $\mathbf{3 6 5}$ & $\mathbf{1 0 0}$ & \\
\hline Number of children & & & \\
1-3 & 128 & 35.1 & 35.1 \\
4-6 & 180 & 49.3 & 84.4 \\
Above 6 & 57 & 15.6 & $\mathbf{1 0 0}$ \\
Total & $\mathbf{3 6 5}$ & $\mathbf{1 0 0}$ & \\
\hline
\end{tabular}

\section{Availability and clarity of the message}

To determine the influence of message content factor. The question on if they had received any message on routine immunisation within the last three months. The results indicated that $56.12 \%$ had received content massage on immunisation while $43.84 \%$ had not received any massage (figure 1). On message clarity, $27 \%$ strongly disagreed, $34.7 \%$ disagreed, $25.7 \%$ were undecided with only $3.82 \%$ strongly agreed. On whether the message was accurate, $32.9 \%$ disagreed, while $39.6 \%$ were undecided, only $13.5 \%$ of the participants agreeing that it was accurate. The mean was 2.93, meaning that the participants did not find the message accurate). $39.2 \%$ is a significant percentage that had not received any message on routine immunisation. The proportion of the population who had received a message on routine immunisation, may translate to knowledge gap and therefore affect adoption of routine immunisation. Message availability is an important attribute in communication process. Message can affect adoption of routine immunisation if the message is not clear, specific, timely and repeated (Oldstein, 2015). Further, another study on the role of communication in adoption of routine immunisation confirmed that message availability is an important attribute in communication process (Asuman et al., 2018).

When the key informant were asked if the Sub-county conducts education sessions on routine immunisation, they affirmed to this, however the majority said that they do not have adequate staff to conduct the session. For example one of the key informant said; 
'As much as we are willing to conduct education sessions, we have a challenge because of the shortage of staff'.

According to them, Health workers, specifically nurses, are the one that conduct health education every morning before the services are offered. When this does not happen for whatever reason, both message availability and frequency is limited and so the client/care giver does not get the information. It follows that they have no chance to get motivation for adoption of routine immunisation. This factor was found to have contributed to the low adoption of routine. When caregiver were asked if the health workers were ready to answer their questions, they strongly disagreed and this can be attributed to the workload and burn out due to personnel shortage.

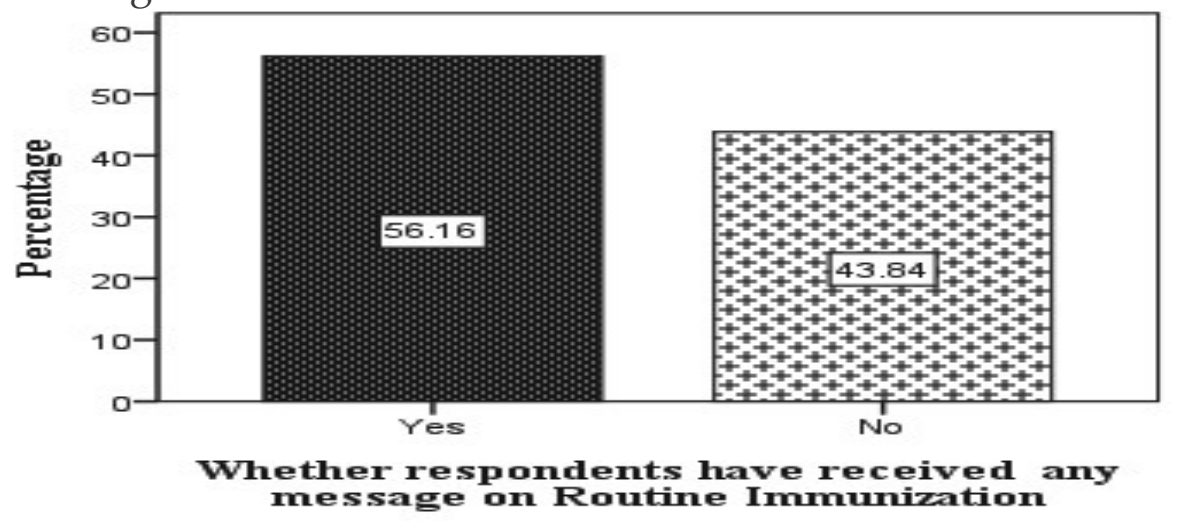

Figure 1: Respondent who had received any message on routine immunisation

\section{Message clarity, authenticity, believability and acceptability}

On whether the message was clear; $27.0 \%$ strongly disagreed, $23.9 \%$ disagreed, $20.3 \%$ were undecided, with 18.0 percentage agreeing and $10.8 \%$ strongly, giving a mean of 2.62 and standard deviation of 1.339. When asked if message was authentic; $21.2 \%$ strongly disagreed, $36.0 \%$ disagreed, $27.5 \%$ were undecided, with only $12.2 \%$ agreed and $3.2 \%$ strongly agreed that it was authentic. The mean was 2.40 . The statement, the message was believable; $26.6 \%$ strongly disagreed, $53.2 \%$ disagreed and $10.4 \%$ were undecided $7.7 \%$ agreed and only $2.3 \%$ of the participants, strongly agreeing and the mean 2.0. When asked if the message was acceptable in their culture, $7.7 \%$ strongly disagreed, 14.7 disagreed, $61.3 \%$ were undecided, $16.2 \%$ agreed, $0.5 \%$ strongly agreed with a mean of 2.90 . These findings shows that since the message was not clear, the participants would not be able to decide on whether it was authentic, believable and acceptable or not. The finding again suggest that the massage was not acceptable (table 5). The fact that large proportion of the population was undecided, on whether the message was acceptable clearly suggest that majority of the population perhaps did not understand the massage content they had received. In a 
study in Nigeria, a scholar attributed the knowledge gap to poor message construction, message that were not tailored to the target audience and poor communication skills on the part of the communicator $(\mathrm{Oku}, 2017)$. Based on these outputs, it was clear that the message was not believable. These findings agrees with those of O'Connell \& Wonodi, (2015), in a study on system strengthening in routine immunisation, with the findings where the researcher found that message availability played a significant role in adoption of routine immunisation.

\section{Message language appropriateness, understandability, respectful and authenticity}

On the statement, the language used was appropriate; $8.1 \%$ strongly disagreed, $36.9 \%$ disagreed, $30.2 \%$ were undecided, $21.2 \%$ agreed, with only $3.6 \%$ strongly agreeing. Giving a mean of 2.75. The participants disagreed on these two statements. The language used in the message was understandable; $14.4 \%$ strongly disagreed, $36.0 \%$ disagreed, $23.9 \%$ were undecided, $15.8 \%$ agreed and $9.9 \%$ strongly agreeing, with a mean of 2.71 . The language in the message was respectful; $14.0 \%$ strongly disagreed, $25.7 \%$ disagreed, $42.8 \%$ were undecided, $15.3 \%$ agreed with $2.3 \%$ strongly agreeing. Giving a mean of 2.66. The statement 'I understood the message on routine immunisation well'; the majority, 37.4\% strongly disagreed, $29.7 \%$ disagreed, $13.5 \%$ were undecided and only $11.7 \%$ agreed and $7.7 \%$ said they strongly agreed, giving a mean of 2.23. The findings showed that the participants did not understand the language. Therefore, they were not sure if the language used was respectively. This could have led to the reason why the message on routine immunisation had the majority of the participants not understanding it well and ended up responding as undecided (table 5). The study shows that there are gaps in message content in terms of attributes of a good communication message. Routine immunisation messages were found to be infrequent and even when it is available, the language used is not clear. This study agrees with a scholars who have stated that, for an effective message, the sender should use clear and simple language understood by the caregivers to enable the caregiver to make informed choices (Olorunsaiye \& Degge, 2016).

Qualitative data further illustrated the gap in conducting routine immunisation awareness in the County. For example, one of the key informant said;

'As much as we are willing to conduct education sessions, we have a challenge because of the shortage of staff since the same nurses who are expected to conduct health educations sessions are the same one expected to attend the clients'.

The above findings mirrors that of Zainabu (2015) who found out that shortage of staff contributed to poor maternal and child services provision in many public health facilities.

Table 5: Message content factors 


\begin{tabular}{|c|c|c|c|c|c|c|c|}
\hline INDICATORS & SD & D & $\mathrm{U}$ & A & SA & MEAN & $\begin{array}{l}\text { STD. } \\
\text { DEV }\end{array}$ \\
\hline $\begin{array}{l}\text { The message was } \\
\text { clear }\end{array}$ & $27.0 \%$ & $23.9 \%$ & $20.3 \%$ & $18.0 \%$ & $10.8 \%$ & 2.62 & 1.339 \\
\hline $\begin{array}{l}\text { The message was } \\
\text { accurate }\end{array}$ & $9.0 \%$ & $32.9 \%$ & $39.6 \%$ & $13.5 \%$ & $5.0 \%$ & 2.73 & .975 \\
\hline $\begin{array}{l}\text { The message was } \\
\text { authentic }\end{array}$ & $21.2 \%$ & $36.0 \%$ & $27.5 \%$ & $12.2 \%$ & $3.2 \%$ & 2.40 & 1.049 \\
\hline $\begin{array}{l}\text { The message was } \\
\text { believable }\end{array}$ & $26.6 \%$ & $53.2 \%$ & $10.4 \%$ & $7.7 \%$ & $2.3 \%$ & 2.06 & .938 \\
\hline $\begin{array}{l}\text { The message was } \\
\text { acceptable in my } \\
\text { culture }\end{array}$ & $7.7 \%$ & $14.4 \%$ & $61.3 \%$ & $16.2 \%$ & $0.5 \%$ & 2.90 & .803 \\
\hline $\begin{array}{l}\text { The language } \\
\text { used was } \\
\text { appropriate }\end{array}$ & $8.1 \%$ & $36.9 \%$ & $30.2 \%$ & $21.2 \%$ & $3.6 \%$ & 2.75 & .996 \\
\hline $\begin{array}{l}\text { The language } \\
\text { used in the } \\
\text { message was } \\
\text { understandable }\end{array}$ & $14.4 \%$ & $36.0 \%$ & $23.9 \%$ & $15.8 \%$ & $9.9 \%$ & 2.71 & 1.188 \\
\hline $\begin{array}{l}\text { The language in } \\
\text { the message was } \\
\text { respectful }\end{array}$ & $14.0 \%$ & $25.7 \%$ & $42.8 \%$ & $15.3 \%$ & $2.3 \%$ & 2.66 & .974 \\
\hline $\begin{array}{l}\text { I understood the } \\
\text { message on } \\
\text { routine } \\
\text { immunisation } \\
\text { well }\end{array}$ & $37.4 \%$ & $29.7 \%$ & $13.5 \%$ & $11.7 \%$ & $7.7 \%$ & 2.23 & 1.274 \\
\hline
\end{tabular}

\section{Logistic regression: Message content and adoption}

The objective was to establish the influence of message content on adoption of routine immunisation of children aged 0-5 years in Bomet County. Logistic regression was conducted and based on this model, an output between message content and adoption of routine immunisation was derived. The output was split into two sections, block 0 and block 1 . Block 0 assessing the usefulness of having a null model, which is a model with no explanatory variables. In this section, the variables in the equation table include a constant only, so every respondent had the same chance of saying Yes or No for the factors that determine adoption of routine immunisation. 
Before the inclusion of the variable (message content), suggest that $53.0 \%$ of the respondents agreed that the children had been immunised (Table 6).

Considering Variables in the Equation table 7, the intercept-only model was $\ln$ (odds) $=.521$. If both sides of this expression were exponentiated, the predicted odds of $[\operatorname{Exp}(B)]=1.127$ was obtained. That is, the predicted odds, of those who agreed to have had their children immunised, was 1.127. Since 194 of the respondents said Yes while 172 said No, the observed odds was 194/172 $=1.127$.

\section{Block 0: Beginning Block}

Table 6: Classification Table for Message content

\begin{tabular}{|c|c|c|c|c|}
\hline & Observed & $\begin{array}{l}\text { Pred } \\
\text { Ado } \\
\text { imm }\end{array}$ & $\begin{array}{l}\text { of routine } \\
\text { on }\end{array}$ & $\begin{array}{l}\text { Percentage } \\
\text { Correct }\end{array}$ \\
\hline $\begin{array}{l}\text { Step } 0 \\
\text { a. Con }\end{array}$ & $\begin{array}{l}\text { Adoption of routine NO } \\
\text { immunisation } \\
\text { Overall Percentage } \\
\text { stant is included in the model. }\end{array}$ & $\begin{array}{l}\text { Yes } \\
0 \\
0\end{array}$ & $\begin{array}{l}\text { No } \\
172 \\
194\end{array}$ & $\begin{array}{c}0.000 \\
100.0 \\
53.00\end{array}$ \\
\hline
\end{tabular}

Table 7: Variables in the Equation for message content

\begin{tabular}{|c|c|c|c|c|c|c|c|}
\hline & & B & S.E. & Wald & Df & Sig. & $\operatorname{Exp}(B)$ \\
\hline Step 0 & Constant & .119 & .135 & .771 & 1 & .380 & 1.127 \\
\hline
\end{tabular}

If the independent variable message content was included in the model, Block 1, which consist of Omnibus test table, model summary, classification table 8 was obtained. The omnibus Tests of Model Coefficients for Message content table displayed the outcome of the Likelihood Ratio (LR) test, which, shows whether the inclusion of the variables in the block contributes significantly to model fit. P-value was employed in making decision, which implies that if $p$-value smaller than 0.05 is recorded then the block 1 under scrutiny is said to be significant in other words block 1 will be an improvement to the block 0 model.

In this study, the inclusion of message content in the model considered the model with no moderator. The omnibus test models for model was significant recorded p-values of 0.000, which are below 0.05. Hence, message content 
significantly affect adoption of routine immunisation of children aged 0-5 years in Bomet County (table 8).

The Summary model table for message content logistic regression model table gives the values for two pseudo R2 (Cox \& Snell R-Square and Nagelkerke R-Square) values, which can be interpreted in a similar way as coefficient of determination in regression models. The two pseudo R2 values measure the extent to which explanatory explains the variation in the dependent variable. The two pseudo R2 were; 0.112 to 0.149 . Therefore it was concluded that between $11.2 \%$ to $14.9 \%$ of the variation in adoption of routine immunisation of children aged 0-5 years in Bomet County was explained by message content (Table 9).

The correct classification rate for the model was recorded and the outcome indicated that classification rate had increased by $8.2 \%$ to $61.2 \%$. Meaning; $61.2-53.0=$ $8.2 \%$. Following inclusion of message content in the block, the relationship between the predictor variable message content and adoption of routine immunisation is given by logistic regression equations expressed as: $\mathrm{Y}=-4.817+1.767 \mathrm{X}_{1}$

The model indicated that for every unit of message content, the value of adoption of routine immunisation of children aged 0-5 years in Bomet County changes by 1.767 (table 10). Therefore, message content had significant positive influence on adoption of routine immunisation of children aged 0-5 years in Bomet County.

Scholars have found that message content has significant influence on immunisation adoption. Oldstein (2015), found that message can affect uptake of vaccination if it is not available, clear, specific and not in a language that the receiver understands. However, Wolicki, J. (2015), in a study found that message content plays a role in adoption of routine immunisation but only if the receiver has prior information and intent on the subject and therefore message only acts as a reminder.

\section{Block 1: Method = Enter (Message content)}

Table 8: Omnibus Tests of Model Coefficients for Message content

\begin{tabular}{|c|c|c|c|c|}
\hline \multicolumn{5}{|c|}{ Model 1} \\
\hline & & Chi-square & Df & Sig. \\
\hline \multirow{3}{*}{ Step 1} & Step & 25.950 & 1 & .000 \\
\hline & Block & 25.950 & 1 & .000 \\
\hline & Model & 25.950 & 1 & .000 \\
\hline
\end{tabular}

Table 9: Model Summary for message content 


\begin{tabular}{lccl} 
Step & -2 Log likelihood & Cox \& Snell R Square & $\begin{array}{l}\text { Nagelkerke } \\
\text { Square }\end{array}$ \\
& & & $\mathrm{R}$ \\
1 & $276.876^{\mathrm{a}}$ & .112 & .149 \\
2 & $237.091^{\mathrm{a}}$ & .259 & .346 \\
a. & Estimation terminated at iteration number 4 because & parameter estimates \\
\multicolumn{3}{l}{ changed by less than .001.}
\end{tabular}

\begin{tabular}{|c|c|c|c|c|c|c|c|}
\hline \multicolumn{8}{|c|}{ Table 10: Model 1 Equation table } \\
\hline & & $\mathrm{B}$ & S.E. & Wald & $\mathrm{Df}$ & Sig. & $\operatorname{Exp}(B)$ \\
\hline \multirow{2}{*}{ Step $1^{a}$} & $\begin{array}{l}\text { Message } \\
\text { content }\end{array}$ & 1.767 & .385 & 21.082 & 1 & .000 & 5.855 \\
\hline & Constant & -4.817 & 1.074 & 20.109 & 1 & .000 & .008 \\
\hline
\end{tabular}

a. Variable(s) entered on step 1: message

\section{Conclusion}

The main objective of this study was to determine persuasive communication factors influencing adoption of routine immunisation of children aged 0-5 years in Bomet County. The specific objectives was to establish the influence of Message content on adoption of routine immunisation of children aged 0-5 years in Bomet County. Analysis using Logistic regression was performed and based on logistic model, the output between predictor variable and adoption of routine immunisation was classified into two sections; Block 0 and Block 1 . Block 0 had no explanatory variables. The study concluded that participants had apathy, nearing to negative attitude towards routine immunisation services. This was demonstrated by the reluctance they demonstrated in answering the questioner, with quite a high number being undecided on even very simple question relating to the study. Message content attributes had positive influence on adoption of routine immunisation and this was the reason for rejection of Null hypothesis; there is no significant influence of message content on adoption of routine immunisation in Bomet County. The study therefore recommended that Bomet County should focus on persuasive communication in order to improve adoption of routine immunisation.

\section{References}

Attah P. Ombugadu (2016). Determinants of routine immunisation coverage among 12-23 months old children of nomadic population in Akwanga local government area, Nasarawa state, Nigeria

Ben C. Anyene (2014). The Role of Politics, Religion and Cultural Practices AJHE2014-Vol 3 (1). African Journal of Health Economics December 2014. 
Bomet County health records (2018). County intergrated development plan 20182022

Derek Asuman, Charles Godfred Ackah and Ulrika Enemark (2018). Inequalities in child immunisation coverage in Ghana: evidence from a decomposition analysis. Health economic review https://doi.org/10.1186/s13561-018-0193-7.

Esohe Olivia Ogboghodo, Hendrith A. Esene, Obehi H. Okujie (2016)/ Determinants of adoption of Pentavalent in Benine City, Southern Nigeria. International Journal of community medicine and Public Health.

Hannah Harvey, Nadja Reisslanda, James Mason (2016). Parental reminder, recall and educational interventions to improve early childhood immunisation uptake: A systematic review and meta-analysis

Hayles, E., Cooper, S., Wood, N., Skinner, S., \& Sinn, J. (2015). Pertussis booster vaccination in pregnancy: Women who had it compared to those who waited. Procedia in Vaccinology, 9, 59-65. https://doi.org/10.1016/j.provac.2015.05.010

Heather Melanie Ames (2017). Mapping, exploring and understanding communication interventions for childhood vaccination

Imoh, G. (2014). Communication Factors That Influence Mothers Decision To Complete Childhood Immunisation In Rural Nigeria. Global Journal of Arts Humanities and Social Sciences, 2(7), 7-17.

Kachikis, A., Eckert, L. O., \& Englund, J. A. (2020). The history of maternal immunisation. Maternal Immunisation, 3-24. https://doi.org/10.1016/b978-0-12814582-1.00001-2

Kaufman, J., Ryan, R., Glenton, C., Lewin, S., Bosch-Capblanch, X., Cartier, Y., ... Hill, S. (2017). Childhood vaccination communication outcomes unpacked and organised in a taxonomy to facilitate core outcome establishment. Journal of Clinical Epidemiology, 84, 173-184. http://doi.org/10.1016/j.jclinepi.2017.02.007.

Kimmel, S. R., \& Wolfe, R. M. (2015). Communicating the benefits and risks of vaccines. Journal of Family Practice, 54(1), S51-58.

Lisa M. Calhoun, Anna M. van Eijk, Kim A. Lindblade, Frank O. Odhiambo, Mark L. Wilson, Elizabeth Winterbauer, Laurence Slutsker and Mary J. Hamel (2014). Determinants and coverage of vaccination in children in western Kenya from a 2003 Cross-Sectional Survey. The American Journal of Tropical Medicine and Hygiene. 2014 Feb 5; 90(2):234241.

O'Connell, M., \& Wonodi, C. (2015). Routine immunisation consultants (RICON) review in Nigeria: A country driven management approach for health systems strengthening in routine immunisation. Annals of Global Health, 81(1), 183. https://doi.org/10.1016/j.aogh.2015.02.920Rogozhina, I. (2018). https://doi.org/10.5194/tc-2018-45-rc2

Oldstein S, MacDonald NE, Guirguis S (2015). Health communication and vaccine hesitancy. 
Olorunsaiye, C. Z., \& Degge, H. (2016). Variations in the Adoption of Routine Immunisation in Nigeria: Examining Determinants of Inequitable Access. Global Health Communication, 2(1), 19-29. http://doi.org/10.1080/23762004.2016.1206780

Ministry of Health Sector Report FINAL - The National Treasury https://www.treasury.go.ke/component/jdownloads/send/211-sector-reports/1489health-sector-report-draft.html 23 Dec 2019 ... 2.2 Expenditure Analysis for FY 2016/17 - 2018/19

Oku, A., Oyo-Ita, A., Glenton, C., Fretheim, A., Ames, H., Muloliwa, A., ... Lewin, S. (2017). Perceptions and experiences of childhood vaccination communication strategies among caregivers and health workers in Nigeria: A qualitative study. PLoS ONE, 12(11), 1-21. http://doi.org/10.1371/journal.pone.0186733

Ouko Julia Awino (2014). Determinants of immunisation coverage among children aged 12-23 months in kenya

Phillips E Vogt (2017). Childhood Vaccines in Uganda and Zambia: Determinants and Barriers to Effective Coverage

UNICEF, (2016). Factors Influencing Vaccine Hesitancy and Immunisation Coverage in Zimbabwe: Ministry of Health, ZIMBABWE, 1(2), 13-475. Wang, Z., \& Zou, Z. (2018). Quantifying multicollinearity in ship manoeuvring modeling by variance inflation factor. Volume 7A: Ocean Engineering. https://doi.org/10.1115/omae2018-77121

WHO, (2018). Systematic literature review of the evidence for effective national immunisation schedule promotional communications. Insights into health communication (Vol. 23).

WHO, (2017). Immunisation Coverage Fact Sheet. Available online: http://www.who.int/mediacentre/ factsheets/fs378/en/

Wolicki, J. (2015). Strategies to Communicate with Vaccine Hesitant Parents Vaccines Are Good Disease is Bad Vaccines protect children from 16 serious diseases Toddler immunisation rates are high Percentage of parents refusing ALL vaccine is small. Journal of the American Academy of Pediatrics, 65(33), 850-858.

Zainabu M., M. (2015). Forgotten roles of health services provision in poor Tanzania: Case of faith based Organisations. Health care facilities in Dodoma region. Science Journal of Public Health, 3(2), 210. https://doi.org/10.11648/j.sjph.20150302.18 